\title{
Democracia, internet e intimidad. ¿Civismo anónimo?
}

\author{
Democracy, internet and intimacy. Anonymous civil service?
}

\author{
Oona Hernández Palma ${ }^{1}$ \\ Universidad Cooperativa de Colombia, Montería, Colombia
}

\author{
Recibido el 30 de noviembre de 2016, aceptado el 15 de enero de 2017 \\ Disponible en internet el 12 de agosto de 2017
}

Resumen: Uno de los grandes aportes del Internet y en especial de la denominada web 2 o social web, es la posibilidad de intercambiar opiniones y retroalimentar la información que en ella se halla, lo cual permite que el hombre acceda a distintas alternativas o herramientas a través de las cuales puede ejercer libremente su derecho a la libertad de expresión. El espacio que propicia el uso del Internet supone muchas formas de interacción, disponibles en cualquier momento y en las que no sólo se accede a información sino que también es posible generar y confrontar la existente. En este escrito, se pone de presente las inquietudes que surgen cuando frente a los riesgos que el Internet genera para el disfrute y protección de los derechos, particularmente el de la intimidad, se propone el anonimato como derecho, asumiéndose como la alternativa jurídica para que la libertad de expresión que alimenta la tecnología, no se debilite o afecte con los actos violentos a los que el ciudadano se expone cuando interactúa en el mundo virtual. El enfoque metodológico abordado es la reflexión alrededor de la admisibilidad de asumir un civismo anónimo en las democracias, se diserta en primer lugar sobre el papel de la libertad de expresión y las posibilidades que ofrece la tecnología para su ejercicio y con ello el rescate de la virtud de los griegos, seguidamente se expone el significado de la participación política y finalmente la fundamentación del anonimato como derecho y su pertinencia en las democracias contemporáneas en donde no es suficiente hablar sino también escuchar en medio de la diferencia y la pluralidad.

Palabras claves. Democracia, ciudadanía, civismo, libertad de expresión, opinión pública, anonimato.

\section{INTRODUCCIÓN}

En la actualidad la vida del hombre se desenvuelve en medio de lo que se ha llamado «mundo digital», para significar el espacio intangible o virtual en el que se pueden realizar innumerables actividades y entablar relaciones que reportan al individuo grandes beneficios a cambio de poca inversión de tiempo e incluso de recursos económicos. Se trata de un mundo que permite la interconexión global gracias al uso de la tecnología y del Internet, lo que ha implicado por ejemplo, amplias posibilidades para el ejercicio del derecho a libertad

\footnotetext{
${ }^{1}$ Correo electrónico: oonaisabel@hotmail.com
} 
de expresión, suponiendo con ello, que la democracia participativa e incluso la deliberativa encuentren hoy una oportunidad para su fortalecimiento, en la medida en que se abren espacios de intercambio de ideas y opiniones.

Sin embargo, a pesar de las ventajas que reporta la tecnología en muchos de los ámbitos en que se desenvuelve el hombre, también puede resultar perjudicial cuando su uso desborda sus «buenos», fines; por lo que el Internet también se constituye como una herramienta en la que se gestan amenazas y violaciones de derechos humanos. Como ocurre por ejemplo; con los derechos a la intimidad, honor, imagen, al buen nombre, datos personales que se ven expuestos permanente y paradójicamente, por la creciente utilidad que genera el Internet en el desarrollo de actividades diarias como el pago de servicios públicos, créditos bancarios, actividades laborales, relaciones interpersonales con las redes sociales virtuales, entre otras.

Es esta dicotomía del Internet y su ineludible uso, la que exige grandes esfuerzos por parte de los Estados para contrastar sus eventuales efectos nocivos, en tanto que el acceso a dicho recurso tecnológico de forma segura, constituye hoy un asunto de primera necesidad, al encontrarnos en medio de la Sociedad de la Tecnología, la Información y la comunicación en la que la ausencia o déficit en estrategias que amplíen la inclusión digital, conlleva a una nueva forma de brecha social y por lo tanto de exclusión. En este escrito se busca poner de presente y reflexionar en torno a las dificultades que puede representar para la llamada democracia y gobernanza digital; los riesgos a los que se ve expuesto el derecho a la intimidad, máxime cuando se propone la configuración del derecho a ser anónimo como alternativa de protección; derivando inquietudes alrededor de lo que hemos denominado como civismo anónimo, categoría discutible dentro de una democracia con fuerza ciudadana y que pretende asumirse como deliberativa.

\section{RESPECTO DE LA LIBERTAD DE EXPRESIÓN Y CIUDADANÍA}

Dentro del marco del Estado Social de Derecho que caracteriza al Estado Colombiano, de acuerdo al artículo primero de la Constitución Política, se protege la libertad de expresión como derecho fundamental y como requisito de la democracia participativa y pluralista que orienta el sistema político, es decir la libertad de expresión es un derecho fundamentalpolítico. La Corte Constitucional Colombiana ha explicado respecto de la naturaleza, alcance y función de la libertad de expresión en una democracia, que: 
[...] Además de su valor intrínseco, cumple funciones de suma importancia en la medida en que las percepciones y decisiones de todo orden de los integrantes de una sociedad dependen de la circulación de múltiples contenidos informativos y del intercambio de pareceres acerca de esa información. Esto es especialmente relevante en el ámbito de lo público. Bajo el orden constitucional vigente la libertad de expresión también está estrechamente relacionada con el principio de igualdad política y con el principio de responsabilidad de los gobernantes ante los gobernados" (Sentencia C-650 de 2003).

Dentro del Sistema Internacional de Justicia, específicamente el Sistema Regional de protección de derechos humanos, la Corte Interamericana de Derechos Humanos ha establecido parámetros de interpretación del derecho a la Libertad de Pensamiento y Expresión consagrado en el artículo 13 de la Convención Americana de Derechos Humanos (Pacto de San José) y ha explicado las dos dimensiones que los justifican y sustentan, individual y social. La primera dimensión, "asegura la posibilidad de utilizar cualquier medio idóneo para difundir el pensamiento propio y llevarlo al conocimiento de los demás. Y a su vez, los receptores potenciales o actuales del mensaje tienen el derecho de recibirlo: derecho que concreta la dimensión social de la libertad de expresión." (García \& Gonza, 2007, p. 18)

Entendida la libertad de expresión y opinión como valor supremo de las democracias, toda vez que se constituyen en el presupuesto que materializan el ejercicio de los derechos políticos; resulta importante buscar maximizar el concepto de ciudadanía que pretende desligar la idea de ciudadano de una visión meramente formalista y asimilarla a un activismo informado, consciente y propositivo en la protección y reconocimiento de derechos y, en la construcción de los asuntos comunes de la ciudad. La comprensión del término ciudadanía no es de manera unificada; por el contrario, ha sido construida en distintos momentos históricos y con influencia de diferentes corrientes políticas, dando lugar a un concepto pluridimensional. En el significado de ciudadanía se establecen tres perspectivas, la de los derechos o estatus legal, la de la participación y el de identidad o pertenencia que establece una línea divisoria entre quienes son o no ciudadanos (Peña, 2008).

En esta oportunidad nos centramos en la dimensión política o de participación de la ciudadanía, en tanto que representa la definición original y en ese sentido constituye la base teórica y práctica de los demás elementos del término; esto es, como estatus legal y como pertenencia a una comunidad política, pues no puede haber un total y pleno reconocimiento 
de los derechos civiles, sociales e incluso políticos si no hay una práctica ciudadana fuerte, activa y educada en los asuntos públicos.

Con la reivindicación de la ciudadanía política se pretenderá resolver, como señala Peña (2008), los problemas de integración cívica, de estabilidad que viven las sociedades democráticas actuales los cuales no pueden resolverse solo con instituciones y leyes, se necesita de un buen ciudadano, quien es más que un titular de derechos y beneficiario de la protección y servicios del Estado; el ciudadano se caracteriza por ciertas actitudes y disposiciones, compromiso y participación en las instituciones, disposición a la deliberación, interés por la cosa pública, etc., es decir, por su virtud cívicas.

La reactivación de las virtudes cívicas implicará mayor participación lo cual afirma Judt “es importante porque no solo aumenta el sentido colectivo de responsabilidad por los actos del gobierno, sino que también contribuye a que los líderes se comporten honestamente y constituye una salvaguarda ante los excesos autoritarios, pues la desmovilización política es una peligrosa pendiente resbaladiza y además es acumulativa porque si nos sentimos excluidos de la gestión de nuestros asuntos colectivos, no nos molestaremos en expresar nuestra opinión sobre ellos y en ese caso, señala, no debería sorprendernos descubrir que nadie nos escucha" (2011, p. 131).

Para Camps (2010, p. 151-174) el problema que enfrentan las democracias de las sociedades liberales actuales, es el de cómo promover el ejercicio cívico de la libertad de expresión toda vez que la conducta del individuo se ve influenciada por los medios de comunicación, el mercado y la apertura tecnológica, lo cual ha provocado que se formen consumidores antes que ciudadanos. Ante esta realidad, Camps (2010), señala que a las sociedades direccionadas por el mercado se agrega la influencia de los avances tecnológicos como el Internet, que no está representando una respuesta de disminución de los niveles de abstencionismo, de ahí que manifiesta que "podemos estar en presencia de lo que "MacLuhan denominó la "aldea global", donde el acceso a los nuevos medios puede ser más global y más plural, pero el resultado puede ser más aldeano, menos ilustrado y más propicio a generar confusión y desorden; pues la libertad de expresión, se ejerce de manera ilimitada e indiscriminada, poniendo en riesgo aún más los valores de la democracia, pues aleja a las personas de su condición de ciudadanos, es decir, conscientes y cumplidoras de sus obligaciones cívicas". 
Por parte de la filosofía política, se acepta la necesidad de recurrir o recuperar las virtudes cívicas para fortalecer esta dimensión de la ciudadanía y por consiguiente, a la democracia, pero teniendo claridad que el fortalecimiento de los deberes cívicos, el interés del ciudadano en los asuntos de la ciudad, es decir, el real ejercicio de la ciudadanía política exige para su concreción práctica un mayor grado de complejidad que las demás dimisiones de la ciudadanía.

No es un simple status que se adquiere cuando otro me lo reconoce y otorga, su sentido va mucho más allá, la ciudadanía es una construcción para dar el paso de la heteronomía a la autonomía ciudadana y para ello se requiere de un proceso de formación, de aprendizaje largo e infinito, en el que de acuerdo a Rubio, se combinan factores cognitivos (instrucción), factores motivacionales (volitivos) y factores conativos (se llega a ser ciudadano ejerciendo la ciudadanía) (2007, p. 159-161); señala el profesor Rubio, "que no se trata de adoctrinamiento como el de los regímenes nacionalistas totalitarios o del comunitarismo fuerte (patriotismos cerrado) o de la democracia populista, porque aunque el proceso de instrucción para una ciudadanía activa implica conocer de modo preciso el alcance de mis derechos y de mis deberes así como el de los demás, de las instituciones y del mismo Estado, nunca, de la manera como se aprende un catecismo o se consulta una Biblia" (2007, p. 160).

En consecuencia, el ejercicio de la libertad de expresión para el fortalecimiento de la democracia, debe ser resultado de una práctica ciudadana, en la que se asume a la ciudadanía como participación política de los asociados en los asuntos públicos, quienes a partir del reflejo de las virtudes cívicas, pretenden una mayor garantía de derechos, derivados de la discusión e intercambio de argumentos a partir del respeto de la diferencia. De tal suerte que, con la democracia digital, las dificultades para la participación ciudadana no obedecen a cuestiones de espacio o tiempo para expresarse libremente, pues con la llegada de la web2 o social web las posibilidades para el intercambio de posiciones son numerosas; sino que por el contrario, el reto que persiste es lograr que el ejercicio de la libertad de expresión sea reflejo de ciudadanía.

\subsection{Democracia, participación política e Internet}

Hemos señalado, que debido al déficit participativo en las democracias contemporáneas, lo cual, además de desnaturalizar su esencia, obstaculiza su fortalecimiento, se ha venido 
promoviendo desde la filosofía política el rescate de la ciudadanía, es decir, de la práctica e intervención de los individuos en los asuntos de la ciudad; de tal manera que sólo es considerado ciudadano quien responda activamente en la conformación, ejecución, control y vigilancia de la gestión pública, vale decir, quien mantenga la virtud cívica como ser coresponsable en la construcción del interés general.

Cuando hablamos de participación en el contexto de las democracias vigentes, resuelta pertinente precisar que la participación política no es exclusiva toda vez que además de ella, encontramos las denominadas comunitaria y social (Gonzalez, 1995, p. 18), y también la que llamamos como participación judicial, para significar la facultad que tienen los individuos en ejercicio de las acciones judiciales constitucionales de reclamar la protección de derechos fundamentales o colectivos que hayan sido vulnerados o estén siendo amenazados o, para a través de la intervención del juez lograr la aplicación de una norma jurídica, que a pesar de estar vigente, la autoridad administrativa no la cumple.

Previo a explicar lo que se entiende por participación política, es pertinente aclarar el significado de participación en sentido general, al respecto resulta apropiado la explicación que da González, cuando afirma que es "una forma de intervención social que le permite a los individuos reconocerse como actores que al compartir una situación, tienen la oportunidad de identificarse a partir de intereses, expectativas y demandas comunes y que están en capacidad de traducirlas en formas de actuación colectiva con una cierta autonomía frente a otros actores sociales y políticos" (1995, p. 15-17).

Por su parte, los profesores Anduiza \& Bosch (2007) plantean la íntima relación que existe entre la democracia y la participación política puesto que el comportamiento ideal dentro de este sistema de comunidad es precisamente el que ésta explica (p.16), y la definen como "cualquier acción de los ciudadanos dirigida a influir en el proceso político y en sus resultados. Anteriormente el análisis se restringía al voto pero posteriormente se empezó a prestar atención a otras formas de acción como el contacto con los políticos y las llamadas formas no convencionales que consistían en las diversas formas de protesta política" (Anduiza \& Bosch, 2007, p. 26).

Sobre los tipos de participación política Anduiza \& Bosch establecen tres modelos dentro de la pluralidad de acciones que despliegan los individuos, a saber: i) Electoral y no electoral, para significar que hay acciones que se desarrollan dentro del marco del proceso 
electoral (votar, participar en mítines, colaborar en una campaña) y otras que están por fuera del mismo, siendo de igual forma esencial para las democracias representativas; ii) Participación convencional y no convencional, según se ajuste o no a las normas sociales y a los valores dominantes de una sociedad (boicot, firma de peticiones) y, iii) Participación basada en la voz y participación basada en la salida (2007, p. 27), dado que existen formas de participación cuya influencia se basa en la comunicación de información (protesta pública, contactos con cargos públicos) y otras que se basan en el ejercicio de la presión con amenazas de irse: por ejemplo, dejar de votar en las elecciones, abandonar un partido en cuyo proyecto ya no se cree (Anduiza \& Bosch, 2007, p. 29).

Con la demanda del Internet a partir de la década de los 60's se empieza a considerar el fortalecimiento de la participación política, especialmente aquella distinta a la electoral, es decir la que busca sentar una voz de protesta y cuestionar el manejo de la cosa pública sirviendo como forma de control ciudadano a los quehaceres de los representante y como herramienta para exigir rendición de cuentas. Con el Internet también se considera la posibilidad de revivir la llamada democracia directa en la medida en que el espacio virtual, al estar al alcance de un amplio sector de la población, podría entenderse como el ágora griega.

Actualmente, Suiza y la ciudad de Porto Alegre en Brasil, representan ejemplos de democracia directa y de participación; aunque con estructuras y fines distintos, son referentes al momento de hablar de este tipo de sistema político y de gobierno distintos a la Grecia clásica. En el caso de Brasil, se toma como objeto de estudio el Presupuesto Participativo de Porto Alegre establecido desde 1989, porque "se trata de una iniciativa política cuya pretensión es que sea la ciudadanía la que seleccione las políticas que se han de llevar a cabo en un determinado espacio" (Rodriguez, 2005, p. 109-110).

El modelo de Porto Alegre y el suizo fomentan la toma de decisiones en la implementación de políticas a partir de la participación ciudadana y con ello fortalece y aumentan los mecanismos de participación al superar los meros electorales. No obstante, estos casos de participación y democracia directa se desarrollan en contextos y con alcances diferentes. En Suiza "la participación ciudadana hace parte del sistema constitucional al introducir la Constitución mecanismos de participación, referéndum e iniciativa legislativa, y en donde 
las leyes promulgadas por el parlamento Federal no están sujetas a ningún tipo de control por parte de los Tribunales" (Soto Barrientos, 2012, p. 375).

En el caso del Sistema de Presupuesto Participativo de Porto Alegre, es un instrumento de izquierda que surge para responder las expectativas de los movimientos sociales, y para que sea la gente la que decida en qué quiere que se gasten las finanzas públicas (Rodriguez, 2005, p. 111). Es decir, no fue producto de un marco normativo previo, sino una práctica propuesta por un movimiento que buscaba mayores garantías de los derechos fundamentales. La finalidad de este mecanismo es para asuntos netamente locales y en relación a la inversión de los dineros públicos, a diferencia del suizo, en donde puede tener la participación ciudadana una proyección para asuntos incluso federales.

Estas experiencias, desarrolladas en países con una forma de Estado distinta a la de Colombia, organizados territorialmente como Estado Federal, hace que la democracia local asuma una dinámica distinta de aquella que existe en la "república unitaria" de Colombia, en donde la "descentralización y autonomía en sus entidades territoriales", no alcanza los niveles que se observan en aquellas, donde cada Estado federado cuenta con sus propios órganos legislativos, judicial y ejecutivo, aunque con respeto a la Constitución Federal. Esta consideración administrativa genera un proceso democrático distinto, que para el caso de los ejemplos de democracia participativa y directa mencionados, ha permitido un avance en el fortalecimiento de la democracia local, reflejándose en especial en Suiza, también a nivel nacional, por las garantías políticas y jurídicas que se determinan desde la Constitución.

Ciertamente, con la tecnología de Internet los usuarios reducen distancia y tiempo, lo cual permite una comunicación rápida, e incluso instantánea entre las personas alrededor del mundo, motivando además el flujo de información y con ello altas posibilidades para el ejercicio de la libertad de expresión, pensamiento y opinión, en un espacio en donde la regulaciones estatales se ven sometidas a una constante revaluación por la complejidad de controlar un espacio, “despaciado", y en donde todos los intervinientes hacen uso de su isegoria (libertad de hablar) de manera plena y absoluta, generando una intervención directa, es decir, sin intermediarios en las discusiones y debates públicos o de interés público. Sin embargo, la eliminación de la democracia representativa en las sociedades actuales y reemplazarla por la directa, la de los atenienses, que renace a partir de la relación 
con el Internet; resulta sólo un deseo que no se ajusta a la realidad en la medida en que olvida las complejidades de los Estados contemporáneos, de millones de individuos, por lo que se requiere una estructura institucional superior a la de Atenas antigua, de aproximadamente cinco mil habitantes.

Con la llamada democracia digital hablamos de ciberciudadanía o de ciberactivismo toda vez que el ciudadano asume su rol en la construcción de ciudad interviniendo en los asuntos públicos de manera activa y propositiva, siendo la interrelación con otros ciudadanos o entre estos y autoridades gubernamentales, con el uso del Internet, mucho más inmediata y oportuna, lo cual brinda enormes posibilidades para que las deficiencias de la democracia sean ser superadas y se convierta a su vez en un efectivo espacio reivindicación de derechos en la medida en que la voz de grupos minoritarios también poder ser escuchadas. De tal manera que consideran algunos que los ideales de la democracia deliberativa pueden encontrar terreno fértil pues el intercambio de ideas goza de gran fluidez con las herramientas tecnológicas. Sin embargo, hay quienes de forma menos alabadora, sugieren que más que deliberación, lo que se cultiva es una democracia agregativa de preferencias (Zambelli, 2014) o en la que los ciudadanos solamente de interesan por aquellos asuntos que le son familiares o próximos (Burguera, 2014).

\subsection{Democracia y derecho a la Intimidad en internet: anonimato}

La democracia digital, donde el Internet se mira como instrumento que permite la reconexión del ciudadano a los escenarios públicos construidos con la tecnología, pretende a partir del poder comunicativo e informativo que ello conlleva, la reconfiguración de la opinión pública y sociedad civil, entendiendo la primera como "aquellas opiniones que asumen cierta relevancia política, que nos implique no sólo como particulares, sino también como ciudadanos, es decir, un público o una multiplicidad de públicos, cuyos estados mentales difusos (opiniones) interactúan con los flujos de información sobre el estado de la cosa pública" (Sartori, 2005, p. 171). Ésta perspectiva del Internet en la democracia, le permite a algunos pensar en la concreción de una democracia deliberativa; sin embargo, algunas posiciones más escépticas consideran que en razón a las complejidades de la comunicación y a las nuevas lógicas mediáticas que no son afables a la deliberación pública, nos encontramos aun distantes de los presupuestos mínimos de la democracia 
deliberativa (Vallespín, 2003, p. 476), que busca el ideal del bien común a partir de un razonamiento entre ciudadanos libres.

Una de las distorsiones a la que se ve expuesto el proceso comunicativo de las personas en la red, son los riesgos y amenazas que se desencadenan para el derecho a la intimidad en la sociedad tecnológicamente desarrollada (Lucena Cid, 2012, p. 126), lo cual ha abonado el camino para considerar que uno de los derechos que tiene quien interactúa en el ciberespacio es a ser Anónimo, el derecho al anonimato. La discusión alrededor de la protección del derecho a la intimidad genera ingentes debates por la dificultad que implica establecer líneas delimitadoras entre lo que es íntimo/privado y lo que es público en una sociedad impulsada por las tecnologías, la información y la comunicación.

Tradicionalmente se ha entendido la intimidad como una zona reservada del ser humano y protegida por el ordenamiento jurídico en la que se brinda resguardo, según Sabater "a un ámbito individual conformado por las relaciones personales y familiares, afectivas y de filiación, las creencias y preferencias religiosas, convicciones personales, inclinaciones políticas, condiciones personales de salud, identidad y personalidad psicológica, inclinaciones sexuales, comunicaciones personales privadas por cualquier medio, la situación financiera personal, familiar y, en síntesis, aquellos actos, acciones, circunstancias que, partiendo de una forma de vida anormal, están reservadas al individuo" (2008).

Los problemas que enfrenta el derecho a la intimidad en la sociedad de la globalización de la información, se asocian con almacenamiento y tratamiento de datos personales, transferencia y difusión de datos a través de tecnologías digitales electrónicas, Internet, redes sociales, videovigilancia de ciudadanos, entre otros; generando el cuestionamiento de si nos encontramos ante un espejismo cuando se habla alrededor de la intimidad y de su protección, pues los espacios de reserva personal o espiritual cada día van cediendo terreno frente a los desarrollos tecnológicos que sumado a los argumentos de conservación del orden público reducen el ámbito de protección. "La tecnología ha introducido cambios integrales en nuestras vidas y en sus diferentes ámbitos de desarrollo (económico, laboral, cultural, cotidiano) ofreciendo nuevas oportunidades y potencialidades, pero generando una mayor vulnerabilidad ante la multiplicación de registros, controles, datos y estadísticas, provocando que las empresas realicen tratamiento de datos que no son perceptibles al usuario" (Sabater, 2008, p. 48). 
En la actualidad los ordenamientos jurídicos se enfrentan a constantes retos por el acelerado crecimiento y desarrollo tecnológico, lo cual dificulta, entre otros asuntos, el deber de los Estados de lograr una eficiente protección del derecho a la intimidad en toda su complejidad. De lo anterior, surgen intentos por redefinirlo para ajustarlo a las nuevas lógicas de las relaciones interpersonales y sociales, donde la exposición del ser humano puede resultar un asunto "normal" o común, como ocurre por ejemplo, frente a las denominadas redes sociales virtuales; por lo que la intimidad entonces, deberá ser estudiada en términos de control en tanto que no sólo es evitar la intromisión de tercero la zona personal reservada, sino es el derecho decidir la exposición de información personal y familiar, en términos de contenido, finalidad y duración.

En su sentido más básico, la privacidad tiene que ver con la capacidad de los individuos de tener control sobre algo. Normalmente este "algo" se entiende como información, es decir, la privacidad es la capacidad de controlar las revelaciones sobre uno mismo, y de controlar cómo y hasta qué punto éstas pueden comunicarse a las demás" (Thompson, 2011, p. 29).

La autodeterminación informativa, como nuevo entendimiento del derecho a la intimidad, ha cimentado la comprensión de la protección de datos personales como derecho independiente a ésta. Aunque como señala Remolina Angarita (2012) "Si bien se trata de dos derechos autónomos no debe perderse de vista que el derecho de protección de datos sigue teniendo su vocación primigenia, mas no exclusiva, de tutelar la privacidad y que en determinadas circunstancias la vulneración de uno acarrea la transgresión del otro. El primero otorga "facultades positivas de disposición y control" de los datos personales, mientras que el segundo confiere "facultades negativas de exclusión y terceros" de la vida privada y familiar de una persona" (p. 5-6).

La Corte Constitucional en su jurisprudencia ha ratificado el carácter autónomo del derecho de protección de datos personales o habeas data, consagrado en el artículo 15 de la Carta fundamental, aunque inicialmente se entendió como parte del derecho a la intimidad, desde 1995 se le ha protegido de manera independiente a la intimidad. Frente a la naturaleza del habeas data, el Tribunal se expresó así en la Sentencia C- 748 de 2011:

[...] Este derecho como fundamental autónomo, requiere para su efectiva protección de mecanismos que lo garanticen, los cuales no sólo deben pender de los jueces, sino de una institucionalidad administrativa que además del control y vigilancia tanto para los sujetos de derecho público como privado, aseguren la observancia efectiva 
de la protección de datos y, en razón de su carácter técnico, tenga la capacidad de fijar política pública en la materia, sin injerencias políticas para el cumplimiento de esas decisiones".

Ante el anterior panorama, del derecho a la intimidad y el derecho a la protección de datos, sustentados en la autonomía personal para controlar mi propia información personal y familiar y decidir cuándo exponerla ante los demás, con la excepciones de Ley; se desprende como opción ante las amenazas de las nuevas tecnologías de vulnerar el derecho a la dignidad humana, vía violación de la intimidad, la posibilidad de interactuar en el espacio digital bajo el anonimato. En el informe presentado por el Doctor Frank La Rue ante la ONU en mayo de 2011 en su condición de Relator Especial para la promoción de los derechos a la libertad de expresión y opinión, manifestó que "el gran potencial y beneficios de Internet tiene su origen en sus características únicas, tales como la velocidad, alcance mundial y el anonimato relativo (La Rue, 2011, p. 7).

Esta perspectiva del anonimato como derecho, ha sido reiterada en el informe presentado en el año 2015 por el Relator Especial para la libertad de expresión y opinión de la ONU, David Kaye, quien ha manifestado que el cifrado y el anonimato son herramientas necesarias en la actualidad como presupuestos a la libertad de expresión y opinión en Internet pues protege a las personas no sólo de terceros sino del mismo gobierno, en tanto que el anonimato permite al usuario para liberar ideas y opiniones más de las que haría si usara su real identidad. A su juicio, el foro público que ha permitido el Internet, debe permitir que el ciudadano disfrute de manera amplia y segura de su libertad de expresión, lo cual es posible mediante el cifrado y el anonimato:

Cuando los Estados imponen la censura ilegal a través de la filtración y otras tecnologías, el uso de la encriptación y anonimato puede empoderar a las personas para sortear barreras y acceder a información e ideas sin la intromisión de las autoridades. Los periodistas, investigadores, abogados y la sociedad civil se basan en el cifrado y anonimato para protegerse (y sus fuentes, clientes y socios) de vigilancia y acoso. La capacidad de buscar en la web, desarrollar ideas y comunicarse de forma segura puede ser la única forma en la que muchos pueden explorar los aspectos básicos su identidad, como es género, la religión, la etnia, el origen o la sexualidad nacional. Los artistas se basan en el cifrado y anonimato para salvaguardar y proteger su derecho a la expresión, sobre todo en situaciones en las que no sólo es el Estado crea limitaciones, sino también la sociedad que no tolera las opiniones poco convencionales o expresión (Kaye, 2015).

Proteger como derecho ser anónimo dentro de la nueva esfera pública, construida con el uso de la tecnología, genera cuestionamientos sobre la naturaleza de ese escenario, en el 
que parece gestarse y desarrollarse las discusiones sobre asuntos de interés común en las sociedades contemporáneas. Este derecho en la red confrontaría el modelo de ciudadanía que se rescata en la actualidad para recuperar la vinculación ciudadana, que responde a la ciudadanía entendida desde su condición política, la cual recoge el papel del ciudadano ateniense, que podemos entender partir de tres características que promueve el humanismos cívico, a saber: "el protagonismo de las personas humanas reales y concretas que toman conciencias de su condición de miembros activos y responsables de la sociedad, y procuran participar eficazmente en su configuración política; la consideración de las comunidades humanas, las cuales superan las actitudes individualistas para actuar como ciudadanos dotados de derechos intocables y de deberes irrenunciables; por último, el humanismo cívico concede un alto valor a la esfera pública concibiéndola como ámbito de despliegue de las libertades sociales y como una instancia de garantía para que la vida de las comunidades no sufra interferencias indebidas ni abusivas presiones de poderes ajenos a ellas" (Llano, 1999, p. 15)

\section{2. ¿Civismo anónimo?}

Ahora bien frente a la real y basta influencia de la tecnología para el desarrollo del derecho a la libertad de expresión, es necesario preguntarnos si la idea de un civismo anónimo ¿resulta admisible dentro de una democracia participativa y pluralista como se asume la colombiana?

La consideración del anonimato como derecho encuentra sustento y justificación en razón a los riesgos que en algunos casos implica, para la integridad y seguridad personal, el libre ejercicio de la libertad de expresión, de tal suerte que la oscuridad resultaría la medida adecuada para garantizarle la libertad a quien considere que de lo contrario su derecho a manifestar sus opiniones se vería limitado o incluso, inexistente. Es decir, el anonimato vendría a proteger la identidad y datos personales a aquellas personas que asumen posiciones contestatarias o de oposición a políticas gubernamentales o en general, posiciones críticas frente al establecimiento, lo cual es propio del régimen democrático.

No obstante, la pregunta debe pensarse también a partir de la naturaleza de la comunicación que se gesta y promueve cuando se acepta el anonimato. La democracia es comunicación, es la isegoria a la que hacían referencia los atenienses clásicos y la que permite el intercambio de opiniones y pensamientos en defensa de un bien común, de tal suerte que 
dicho intercambio implique aceptación y respeto a la diferencia, entendiendo que el contradictor no es un enemigo; todo lo contrario, es un alter ego cuyas ideas no deben ser violentadas. ¿La comunicación política que nace desde una máscara o guarida puede ser capaz de generar opinión pública que impulse una democracia deliberativa?

La comunicación política no es aquella que promueve el gobierno para dar a conocer sus actuaciones y tampoco aquella propaganda política de los partidos, aunque debido al crecimiento e influencia de los medios de comunicación, es ese el significado que se ha venido asimilando (Burguera Ameave, 2014). El significado de comunicación política debe abarcar o incluir el papel del ciudadano y es ese sentido generar opinión pública, es decir, aquella que nutre el espacio público a partir del intercambio de ideas con argumentos, es decir, "aquellas opiniones que asumen cierta relevancia política, que nos implique no sólo como particulares, sino también como ciudadanos, vale decir, un público o una multiplicidad de públicos, cuyos estados mentales difusos (opiniones) interactúan con los flujos de información sobre el estado de la cosa pública. Es en este último aspecto, y por este motivo, por lo que la teoría de opinión publica se convierte en parte constituyente de la teoría de la democracia” (Sartori, 2005, p. 171).

Bajo la anterior perspectiva, resulta dudoso pensar que el anonimato contribuye a cultivar o bien fortalecer las virtudes cívicas, en la medida en que la comunicación o ideas que se expresen desde esa posición para opinar sobre la cosa pública, pueden estar creando un espacio público teatral más que político y deliberativo, en tanto que la dificultad de identificar al interlocutor no da muestra de que con ello permita fomentar el respeto de lo diferente, sino que por el contrario, se visualizará mucho más la violencia e intolerancia en la red. Sin embargo, otros señalan que "esta forma de interacción en la red satisface la necesidad humana de ser visto y reconocido, al mismo tiempo que preserva la intimo. La máscara permite nuevas formas de socialidad que libera del riesgo de la ridiculez y permite al mismo tiempo la expresión de emociones externas, de pensamientos que, de otra manera, quedarían asfixiados por la censura de lo políticamente correcto" (García Leguizamón, 2008, p. 613-615)

Consideramos que entender la esfera pública como es espacio teatral, donde el interlocutor puede esconderse detrás de un personaje, no es más que una ilusión que sólo es admisible si se trata de un juego entre personajes, temporal e irreal, ajeno a un efectivo empoderamiento 
ciudadano. Creemos que la espera política, entendida como esfera dramaturgia resultado de la comunicación mediante computador, contribuiría a la degeneración de la esfera pública que como advierte Habermas (1962), viene desde la mercantilización de la labor de los medios de comunicación; toda vez que el ciudadano no sólo será un consumidor más sino que además un individuo amparado en un disfraz que bajo su escondite, o derecho al anonimato, representará sólo un personaje que no puede ajustarse al sentido cívico de ciudadanía.

La influencia del Internet en la democracia debe abordarse desde la necesidad de reforzar los deberes cívicos del ciudadano, es decir, aquel que se involucra y promueve la participación política como alternativa en la protección y reivindicaciones sociales. De lo contrario, la posibilidad de evadir su identidad acrecentará el infotainment del que Vallespín (2003) habla para referirse a que en "la política crece más interés cuanto más se regocija en el escándalo y vulnera o se aparta de las normas establecidas, lo pautado o, más recientemente, lo políticamente correcto". Agrega que del panóptico hemos pasado así al sinóptico, a una sociedad donde el interés público parece coincidir con la posibilidad de ejercer un sistemático voyerismo de todo lo privado donde los personajes populares lo son en gran medida por el mero hecho de aparecer, no por sus méritos intrínsecos. El interés público se define así más por la curiosidad que suscitan los vicios o desdichas privadas que por remitir a algo que nos es común (Vallespín, 2003, pág. 470).

\section{A MODO DE CONCLUSIÓN}

En tiempos en que las Tics representan un alto valor para el desarrollo de las actividades del hombre en la sociedad y particularmente al ser asumidas como en pieza fundamental en la comunicación humana, resulta poco afortunado negar las oportunidades que el Internet y la tecnología ofrecen para que con la interacción e interconexión que permite, se eleven los niveles de participación política de los ciudadanos y ello se traduzca en una democracia de calidad. La comunicación política se constituye en la columna vertebral de la democracia en tanto que el intercambio de ideas sobre los asuntos comunes o públicos sienta las bases para la generación de opinión pública que deberá orientar el quehacer del gobierno en turno.

Sin embargo, frente a las visiones «ciberoptimistas», es decir aquellas que depositan una alta confianza en las herramientas tecnológicas y en especial en el Internet para pretender 
derivar de ello una mejor democracia, surgen otras que con menos euforia se cuestionan sobre la calidad de la opinión que la participación digital genera. Es decir, si puede ser considerada como opinión pública y libre, si en efecto estamos frente a la isegoria de los griegos en la que no solamente se habla sino que también se escucha y además, en la que los ciudadanos encuentren con el ejercicio de su libertad de expresión un verdadero poder de emancipación para provocar mayores y mejores reivindicaciones sociales en la protección de derechos.

En esta reflexión se ha pretendido exponer las inquietudes que se tejen en torno a la calidad que la democracia digital, en particular, a partir de los riesgos que el uso del Internet implica para el derecho a la intimidad y datos personales, provocando que el anonimato se constituya en la alternativa que permitiría el pleno ejercicio de la libertad de expresión, vale decir, con seguridad, en tanto que la identidad queda resguardada frente a los eventuales ataques o actos de ciberviolencia de los que pueda ser objeto el titular del derecho. Y las dudas surgen cuando se pregunta si es posible asumir un civismo anónimo que fortalezca la democracia no solo mirando los niveles de participación ciudadana, sino también en la generación de opinión pública que propicie una deliberación; o si por el contrario, la configuración del derecho al anonimato es la legitimación de la violencia que se cultiva en la red.

\section{Referencias}

Anduiza, E., \& Bosch, A. (2007). Comportamiento político y electoral. Barcelona: Ariel.

Burguera Ameave, L. (2014). Subjetividad instatánea en la ficción del nuevo espacio público. En R. Cotarelo, \& J. Olmeda (Edits.), La Democracia del siglo XXI. Política,medios de comunicación, internet y redes sociales (págs. 107-121). Madrid: Centro de Estudios Políticos y constituionales.

Camps, V. (2010). El ejercicio cívico de la libertad de expresión. En V. Camps (Ed.), Democracia sin ciudadanos. La construcción de la ciudadanía en democracias liberales (págs. 151174). Madrid: Trotta.

Corte Constitucional de Colombia. Sentencia C-650 de 2003 (M.P. Manuel José Cepeda Espinosa: agosto 5 de 2003) 
Corte Constitucional de Colombia. Sentencia C-748 de 2011 (M.P. Jorge Ignacio Pretelt Chaljub: octubre 6 de 2011)

García Leguizamón, F. (2008). La esfera de la público y las tecnologías de la comunicación. En A. Rocha de la Torre (Ed.), La responsabilidad de pensar. Homenaje a Guillermo Hoyos Vásquez (págs. 573-616). Barranquilla: Ediciones Uninorte.

García Ramirez, S., \& Gonza, A. (2007). La Libertad de Expresión en la jurisprudencia de la Corte Interamericana de Derechos Humanos. Mexico: Corte Interamericana de Derechos Humanos.

Gonzalez, E. (1995). Manual sobre participación y organización para la gestión local. Santiago de Cali: Foro Nacional de Colombia.

Habermas, J. (1962). Historia y crítica de la opinión pública. Barcelona: G Gili S.A.

Judt, T. (2011). Algo va mal. Bogotá: Taurus.

Kaye, D. (2015). Informe del Relator Especial para la promoción de la libertad de expresión y opinión. Recuperado el 30 de Junio de 2015, de http://www.ohchr.org/EN/Issues/FreedomOpinion/Pages/CallForSubmission.aspx

La Rue, F. (2011). Informe del Relator Especial sobre la promoción y protección del derecho a la libertad de opinión y de expresión. Nueva York: ONU. Recuperado el Julio de 2014, de http://ap.ohchr.org/documents/dpage_s.aspx?m=85

Llano, A. (1999). Humanismo Cívico. Barcelona: Ariel.

Lucena Cid, I. V. (2012). La protección de la intimidad en la era tecnológica: hacia una reconceptualización. Revista Internacional de Pensamiento político, 7, 117-144. Recuperado el 10 de Diciembre de 2014, de http://www.pensamientopolitico.org/Descargas/RIPP07117144.pdf

Peña, J. (2008). Nuevas perspectivas de ciudadanía. En F. Quesada (Ed.), Ciudad y Ciudadanía. Senderos contemporáneos de la filosofía política (págs. 231-252). Madris: Trotta.

Remolina Angarita, N. (Julio-diciembre de 2012). Aproximación constitucional de la protección de datos personales en Latinoamérica. Revista Internacional de Protección de datos personales(1), 1-13. Recuperado el 10 de Enero de 2015, de http://habeasdatacolombia.uniandes.edu.co/wp-content/uploads/7_-Nelson-Remolina.pdf 
Rodriguez, R. (2005). Ciudadanos Soberanos. participación y democracia directa. España: Almazura.

Rubio Carracedo, J. (2007). Teoría crítica de la ciudadanía democrática. Madrid: Trotta.

Sabater, M. D. (2008). Vidas de Cristal. Análisis del derecho a la intimidad en la sociedad de la información. intersticios. Revista Sociológica de pensamiento crítico, 2(1), 43-54. Recuperado el 10 de Diciembre de 2014, de http://www.intersticios.es/article/view/2202

Sartori, G. (2005). Elementos de teoría política. (M. L. Morán, Trad.) Madrid: Alianza.

Soto Barrientos, F. (2012). La democracia como forma de Estado: Análisis de los mecanismos de particpación directa en la constitución Suiza. Estudios Constitucionales(1), 373-402. Recuperado el 10 de Diciembre de 2014, de http://www.scielo.cl/scielo.php?pid=S071852002012000100010\&script=sci_arttext

Thompson, J. (Enero-junio de 2011). Los límites cambiantes de la vida pública y la privada. Comunicación y sociedad(15), 11-42. Recuperado el 23 de Enero de 2013, de http://www.scielo.org.mx/scielo.php?pid=S0188-252X2011000100002\&script=sci_arttext

Vallespín, F. (2003). Un nuevo espacio público: la democracia médiatica. En A. Arteta , E. García Guitán, \& R. Máiz (Edits.), Teoría política: poder, moral, democracia (págs. 462-477). Madrid: Alianza. 